\title{
Highly Efficient Dye-sensitized Solar Cells Based on Poly(vinylidene fluoride-co-hexafluoropropylene) and Montmorillonite Nanofiller-based Composite Electrolytes
}

\author{
Liang-Huei Chen ${ }^{1 *}$, Shanmuganathan Venkatesan ${ }^{2 *}$, I-Ping Liu ${ }^{2}$, and Yuh-Lang Lee ${ }^{2,3 *}$ \\ ${ }^{1}$ Department of Medicinal Chemistry, Chia Nan University of Pharmacy and Science, Tainan 71710, TAIWAN \\ ${ }^{2}$ Department of Chemical Engineering, National Cheng Kung University, Tainan 70101, TAIWAN \\ ${ }^{3}$ Hierarchical Green-Energy Materials (Hi-GEM) Research Center, National Cheng Kung University, Tainan 70101, TAIWAN
}

\begin{abstract}
Highly efficient nanocomposite electrolytes were prepared by mixing the montmorillonite (MMT) clay nanofillers and iodide poly(vinylidene fluoride-co-hexafluoropropylene (PVDF-HFP) gel electrolytes for the purpose of measuring the performance of quasi-solid-state dye-sensitized solar cells (QS-DSSCs). The impacts of different amounts of MMT nanofillers on the ion diffusivity, conductivity of the polymer gel electrolytes (PGEs), and the photovoltaic performance of the cells using the PGEs were evaluated. The results indicated that the use of $5 \mathrm{wt} . \%$ MMT markedly increase the ion diffusivity and conductivity of the PVDF-HFP PGE. The introduction of $5 \mathrm{wt}$ \% nanofillers considerably reduced the Warburg diffusion resistance, which made to the high performance of the QS-DSSCs. Cells utilizing 5 wt.\% MMT nanofillers were shown to obtain a power conversion efficiency (PCE) $(6.77 \%)$ higher than that obtained for cells using pure PGEs and identical to that obtained using liquid electrolytes (LEs) $(6.77 \%)$. The high PCE was a result of an enhance in the current density in the presence of the $5 \mathrm{wt} . \%$ MMT nanofillers. The DSSC efficiency was found to maintain $99.9 \%$ of its initial value after $194 \mathrm{~h}$ of testing at $60^{\circ} \mathrm{C}$ under dark environments. The stability of the DSSC using PGEs with the optimal amount of MMT nanofillers was higher than that for the cells using liquid electrolyte and pure PGE.
\end{abstract}

Key words: poly(vinylidene fluoride-co-hexafluoropropylene), montmorillonite, nanofiller, iodide liquid electrolytes,

dye-sensitized solar cells

\section{Introduction}

Dye-sensitized solar cells (DSSCs) have acquired significant interest over the last twenty years both in academia and industrial research. They are expected to be a plausible substitute for classical photovoltaic devices due to their good power conversion efficiency (PCE), low production cost, and potential for designing colorful, transparent $\operatorname{DSSCs}^{1-5)}$. DSSCs with PCEs of up to $12 \%, 13 \%$, and $14 \%$, respectively, have been fabricated based on ruthenium complex, zinc porphyrin, and organic dyes ${ }^{6-8)}$. In these types of DSSCs, a high volatile organic solvent such as acetonitrile-based liquid electrolyte (LE) is generally used. However, LEs cause leakage of the electrolytes and evaporation of solvents, particularly at elevated temperatures, both of which reduce the lifetime of the DSSCs ${ }^{9}$. Therefore, appropriate sealing techniques are always required when preparing liquid-state cells. Low-volatility solvents such as 3-methoxy propionitrile (MPN) are also typically used for the preparation of stable liquid-state cells. However, MPN solvents significantly decrease DSSC PCEs. To control this leakage and evaporation, several solid-state and quasi-solid-state materials are utilized instead of $\mathrm{LEs}^{10-14)}$. Cells using these materials have high lifetime even at high temperatures. However, the PCEs of these cells are markedly lower than those of LEs. This is because of their low ionic conductivity and their lack of contact with the electrodes $^{15)}$.

To overcome these problems, polymer-based electrolytes (PEs) have been introduced for DSSC applications ${ }^{16,17}$. In the PEs, LEs are retained in the polymer matrices and thereby minimize evaporation of the solvents and also enhance the stability of the DSSCs. Besides, redox couples are rapidly moved in the PEs through the cages formed by polymer networks, thereby conductivity improving the

*L.-H Chen and S. Venkatesan Contributed equally to this work

*Correspondence to: Yuh-Lang Lee, Department of Chemical Engineering, National Cheng Kung University, Tainan 70101, TAIWAN

E-mail: yllee@mail.ncku.edu.tw

Accepted November 29, 2019 (received for review November 5, 2019)

Journal of Oleo Science ISSN 1345-8957 print / ISSN 1347-3352 online

http://www.jstage.jst.go.jp/browse/jos/ http://mc.manusriptcentral.com/jjocs 


\section{L.-H. Chen, S. Venkatesan, I-P. Liu et al.}

characteristics of the electrolytes and the PCEs of the cells. In some reports, polymer gel electrolytes (PGEs) with in-situ gelation features as well as electron spun membrane PGEs were proposed to improve the contact of the electrolyte with the photoelectrodes ${ }^{18-20)}$. Although PEs have several advantages over other electrolytes, the PCEs of cells using PEs are lower than those in cells using LEs because of the hindrance of ionic movements by the polymer matrices.

In recent years, nanocomposite electrolytes (NCEs) have received significant attention as an alternative for liquids, solids, and $\mathrm{PEs}^{21)}$. NCEs are prepared by mixing several kinds of nanosized materials or nanofillers into LEs, ionic LEs and PEs. The presence of nanofillers was shown to markedly improve the performance of the electrolytes in cells. Cells using NCEs have much higher efficiency and stability as compared to their related liquid counterparts. In the literature, printable electrolyte pastes with nanofillers have been utilized for the preparation of sub-module $\mathrm{DSSCs}^{22-25)}$. By using this printing process, printable electrolyte pastes are applied on the surface of the photoelectrode. Under one-sun and room light conditions, these cells also obtain high PCEs ${ }^{24,25)}$. It is well known that montmorillonite (MMT) in various forms, including exfoliated, intercalated, and organic molecularly-modified MMT, have been used as nanofillers in the DSSC electrolytes for several years $^{26-30)}$. Each form of MMT nanofillers has its own effects on the characteristics of the electrolytes as well as the photovoltaic performance of the cells. Cells using PEs with exfoliated MMT nanofillers and un-modified MMT nanofillers have been found to achieve PCEs of $5.2 \%$ and $4.70 \%$, respectively $^{27,28)}$.

In this study, iodide NCEs were prepared for the preparation of QS-DSSCs to operate effectively under one-sun conditions. The PGE was first prepared by solidifying MPNbased iodide electrolytes with poly (vinylidene fluoride-cohexafluoropropylene (PVDF-HFP) . An unmodified aluminium pillared-MMT was then added to the PVDF-HFP PGE to acquire the NCEs. To obtain high cell performance, the concentration of the MMT in the PGEs was regulated. The QS-DSSC using the best conditions demonstrated high cell efficiency and stability.

\section{Experimental Section}

\subsection{Materials and methods}

PVDF-HFP, $\left(M_{\mathrm{w}}=400,000\right)$, 1,3-dimethyl-imidazolium iodide(DMII, >98\%), lithium iodide (LiI, 99\%), 4-tert-butylpyridine ( $t$ BP, $99 \%$ ), MMT (Aluminium pillared clay), guanidine thiocyanate(GuSCN, 99\%) and 3-methoxypropionitrile (MPN, 99\%) were obtained from Sigma Aldrich. Surlyn films (25 $\mu \mathrm{m}$ thick, Meltonix 1170-60) and Ruthenizer 535-bis TBA (N719, 99\%) were purchased from Solaro- nix, Ethanol and Titanium(IV) chloride $\left(\mathrm{TiCl}_{4}, 99 \%\right)$, respectively, were received from J. T. Baker and Acros Organics. Titanium dioxide $\left(\mathrm{TiO}_{2}\right)$ pastes such as PST 400C and PST 18NR were acquired from Catalysts \& Chemicals Industries Co., Ltd. Conductive glass (Fluorine doped tin oxide (FTO, TEC 7, 2.2 NM THICK, $7 \mu \mathrm{m}$ Sqm) was obtained from the Hartford Glass Co., Ltd. All chemicals and material were utilized as obtained unless otherwise indicated.

\subsection{Preparation of the electrolytes}

High boiling point solvent MPN was utilized for the preparation of the liquid and gel-electrolytes. The LEs were prepared by dissolving 0.8 M DMII, 0.1 M LiI, $50 \mathrm{mM} \mathrm{I}_{2}, 0.5$ $\mathrm{M} t \mathrm{BP}$, and $0.1 \mathrm{M}$ GuSCN in MPN. To prepare the PGEs, 9 wt. \% PVDF-HFP was introduced into the LEs, and then the mixture was heated slowly to $120^{\circ} \mathrm{C}$ with constant stirring until the polymer completely dissolved in the LEs. For the preparation of the NCEs, MMT nanofillers were added to the polymer and LE mixture. The mixture was heated to $110^{\circ} \mathrm{C}$ and underwent slow stirring for $2 \mathrm{~h}$ to obtain welldispersed MMT nanofillers into the PE solution. For the optimization experiments, different amounts of MMT nanofillers were dispersed into the PGEs

\subsection{Preparation of the cells and measurements}

The cells were prepared based on the following procedures: Both the photoanode and counter electrode (CE) were prepared using conductive glass, Before the preparation of the DSSCs electrodes, the FTO glass was cleaned sequentially with a neutral cleaner, deionized water, acetone, and isopropyl alcohol. An $8 \mu \mathrm{m}$ thick $\mathrm{TiO}_{2}$ main layer and a $4 \mu \mathrm{m}$ thick $\mathrm{TiO}_{2}$ scattering layer, respectively, using the PST-18NR and PST-400C $\mathrm{TiO}_{2}$ pastes were printed on the clean FTO glass. A $12 \mu \mathrm{m}$ thick $\mathrm{TiO}_{2}$ layer was heated to $500^{\circ} \mathrm{C}$ in an oxygen environment followed by sintering at the same temperature for thirty minutes. After the sintering process, the $\mathrm{TiO}_{2}$ electrode was cooled to $80^{\circ} \mathrm{C}$ and then dipped into the N719 dye solution in ethanol $(0.3 \mathrm{mM})$ for $20 \mathrm{~h}$ at room temperature. After dye-adsorption, the photoelectrode was washed with ethanol and dried. The active area of the DSSCs was $0.16 \mathrm{~cm}^{2}$.

For the liquid and PE filling, two holes were drilled into the conductive side of the FTO glass. Platinum (Pt) layer was sputtered on the drilled side of the FTO glass. Fabrication of the DSSCs was carried out by sandwiching the dyesensitized photo electrode and Pt-CE with a $30 \mu \mathrm{m}$ thick spacer using a hot pressing technique. The liquid, polymer, and NCEs were placed into the device through the predrilled holes.

The current density-voltage $(J-V)$ features of the DSSCs using the liquid and PGEs were determined under one-sun conditions with a light intensity of $100 \mathrm{mWcm}^{-2}$ using a solar simulator coupled with a digital source meter. Cyclic 
voltammetry (CV) and electrochemical impedance spectroscopy (EIS) were utilized to measure the ionic diffusivity and conductivity, respectively, of the symmetric dummy cells using the LEs, PEs, and NCEs. The cells were prepared based on two identical Pt-coated FTO substrates sandwiched using a $60 \mu \mathrm{m}$ thick Surlyn spacer. The EIS curves of the symmetric dummy cells were measured at open circuit potential using a potentiostat(PGSTAT30, Autolab) connected with an FRA module, operating at a frequency ranging from $0.1 \mathrm{~Hz}$ to $100 \mathrm{KHz}$ at a potential modulation of $10 \mathrm{mV}$. EIS analysis on QS-DSSCs with and without 5 wt.\% MMT nanofillers were carried out under dark conditions. These cells were operating at a frequency ranging from $20 \mathrm{mHz}$ to $65 \mathrm{KHz}$.

\section{Results and Discussion}

\subsection{Influence of MMT nanofillers on the Ion diffusivity and Conductivity of the PVDF-HFP PGEs}

It is well known that the ion diffusivity and conductivity of PGEs are the important characteristics deciding the PCE of cells ${ }^{23,24)}$. To study the influence of MMT nanofillers on the ion diffusivity and conductivity of PGEs, an iodide PGE was first prepared using $10 \mathrm{wt} \%$ PVDF-HFP based on the published reports in the literature ${ }^{20,21)}$. Then, different concentrations of MMT (5-25 wt.\%) nanofillers were mixed into the PVDF-HFP PGE. The overall schematic picture of the structure of PVDF-HFP polymer MMT composite electrolyte is given in Fig. 1. For the measurement of the ion diffusivity and conductivity of the electrolytes, symmetric dummy cells assembled using the PGEs with and without nanofillers were utilized. These cells were subjected to a CV analysis to evaluate the ion diffusivity in the electrolytes. The diffusion-limited current was calculated from the cyclic voltammograms measured for the electrolytes at a scan rate of $8 \mathrm{mV} \mathrm{s}^{-1}$. From the diffusionlimited current, the ion diffusivity was calculated. The ion diffusivities estimated for the PGEs without and with different amounts of MMT nanofillers are given in Fig. 2. The diffusivity was $6.77 \times 10^{-6} \mathrm{~cm}^{2} \mathrm{~s}^{-1}$ for the pure PGE, which increased to $7.32 \times 10^{-6} \mathrm{~cm}^{2} \mathrm{~s}^{-1}$ in the PGEs containing 5 wt.\% MMT nanofillers. The results indicate that even the addition of a small amount of MMT nanofillers enhances the ion diffusivity of the PGEs. It has been reported that the introduction of clay nanofillers in PE causes the dissociation of lithium salts and reduces the ion-pair forma$\operatorname{tion}^{29)}$. This effect can be responsible for the dissociation of lithium iodide and retention of a large amount of iodide ions in PGEs. Therefore, the ion diffusivity was increased in the presence of a small amount of MMT nanofillers. However, with further increases in the MMT nanofillers from 10 to 25 wt.\% the ion diffusivity gradually decreased in the PGE.
The conductivities of the PGEs with and without nanofillers were assessed to know the role of MMT nanofillers on the charge transport. The EIS technique was utilized to perform the conductivity experiments in the symmetric dummy cells using the electrolytes. The conductivity was $1.0 \times 10^{-3} \mathrm{~S} \mathrm{~cm}^{-1}$ in the pure PVDF-HFP PGE. With the introduction of the MMT nanofillers, the conductivity first increased and then reduced after attaining a high value of 2.2 $\times 10^{-3} \mathrm{~S} \mathrm{~cm}^{-1}$ at $5 \mathrm{wt}$.\% MMT. Although the presence of higher amounts of MMT nanofillers in the PGEs decreased the electrolyte conductivity, these conductivity values were not lower than those for the pure PGEs. The effect of the amount of the MMT nanofillers on the conductivity of the PVDF-HFP PGE was identical to that of ion diffusivity in terms of a tendency towards increases and decreases. For the 5 wt.\% MMT, the conductivity and ion diffusivity had higher values than those found for the pure PVDF-HFP PGEs. These outcomes indicate that charge transport and ionic conductivity are mostly correlated with ion diffusivity. The electrolyte conductivity increased due to the added MMT, which might have affected the kinetics of the PVDFHFP polymer chain and facilitated localized amorphous regions. The highly amorphous characteristics of the PVDF-HFP assisted with the uptake of more LEs. The iodide/triiodide redox couples could quickly pass into the liquid like an amorphous structure. Therefore, the addition of MMT NFs in the electrolytes triggered an increase in the ion diffusivity and electrolyte conductivity. When the introduction of MMT surpassed 5 wt.\%, it decreased the electrolyte conductivity owing to the negative impact of the MMT nanofillers since higher MMT concentrations triggered the agglomeration of polymer chains. As a result, the rate of recrystallization was enhanced. The crystalline phase of PVDF-HFP PGE retarded the ion transport. Consequently, the electrolyte conductivity and ion diffusivity also decreased beyond the optimal amount of MMT, as shown in Fig. 2.

\subsection{Influence of the MMT nanofillers on the PCE of the PVDF-HFP-based cells}

Photovoltaic parameters such as the current density $\left(J_{\mathrm{sc}}\right)$, open-circuit voltage $\left(V_{\mathrm{oc}}\right)$, fill factor $(\mathrm{FF})$, the PCE of the DSSCs using LEs, and PVDF-HFP PGEs without and with 5-25 wt.\% of MMT derived from the $J-V$ curves are presented in Table 1. The PCE acquired for the DSSCs using LEs was $6.77 \%$, which decreased to $6.28 \%$ for the DSSCs using pure PGEs. The PCE of the DSSC enhanced with the addition of MMT nanofillers in the PGE, attaining a high value of $6.77 \%$ at 5 wt.\% MMT. This PCE was similar to that of the DSSCs using LE. This PCE is higher than the reported efficiency of the DSSC (5.2\%) using modified MMT-based NCE in the literature ${ }^{28)}$. The PCE decreased afterwards with another increase in the amount of MMT nanofillers. Table 1 indicates that the presence of 5 
(a)
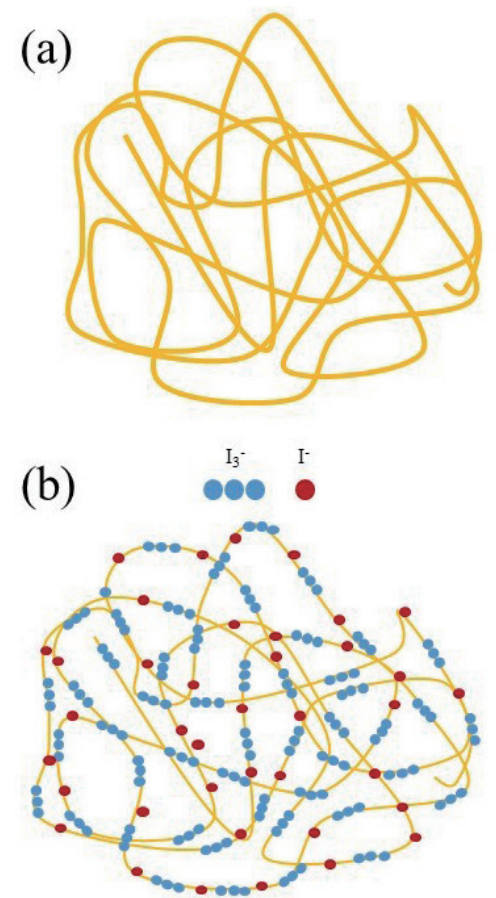

(c)

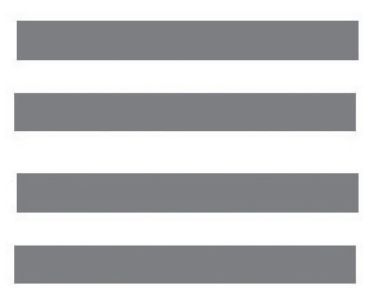

(d)

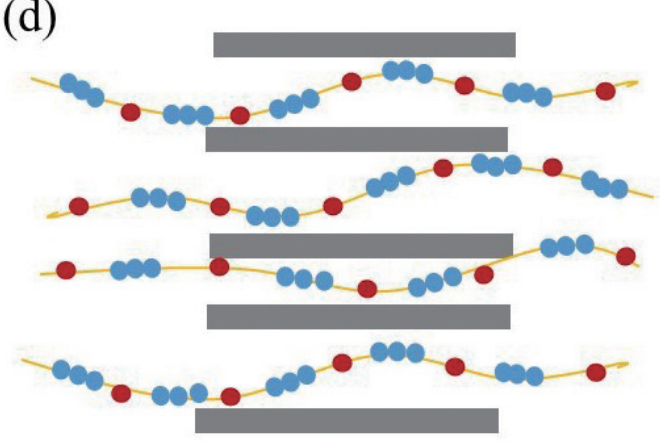

Fig. 1 Schematic picture of the structure of (a) PVDF-HFP polymer, (b) iodide PVDF-HFP PGE, (c) MMT and (d)iodide PGE intercalated MMT.

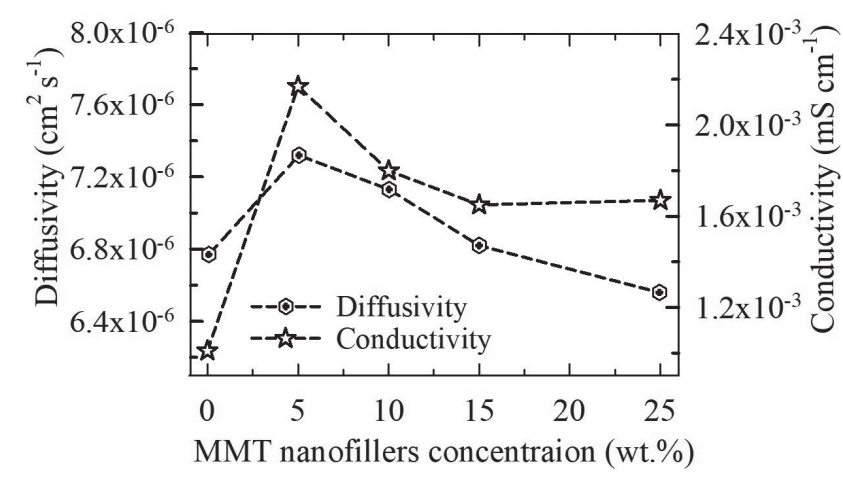

Fig. 2 Ion diffusivities and conductivity of the PGEs with 0-25 wt.\% of MMT nanofillers.

wt.\% MMT nanofillers in the PGEs caused an increase in the $J_{\text {sc }}$, but a significant decrease in $V_{\text {oc }}$ and a slight decrease in FF. Since the $J_{\text {sc }}$ was enhanced markedly more than the $V_{\text {oc, }}$, and the FF was decreased, the PCE improved owing to the presence of the $5 \mathrm{wt}$ \% MMT nanofillers. The QS-DSSCs utilizing different amounts of MMT nanofillers had higher $J_{\text {sc }}$ values than was the case for the cells using pure PVDF-HFP PGEs. A high $J_{\mathrm{sc}}$ value of $15.15 \mathrm{~mA} / \mathrm{cm}^{2}$ was achieved for the QS-DSSC using 5 wt.\% MMT nanofillers. This value was even higher than that acquired for a cell using LEs $\left(14.10 \mathrm{~mA} \mathrm{~cm}{ }^{-2}\right)$. The high $J_{\mathrm{sc}}$ was ascribed to the high ion diffusivity and electrolyte conductivity in the presence of the $5 \mathrm{wt}$ \% MMT. As a result, a much better PCE was acquired for the QS-DSSC using $5 \mathrm{wt}$ \% MMT compared to the cells using the LEs, pure PGE, and
PGE with 5-25 wt.\% MMT. The decrease in the $V_{\text {oc }}$ was ascribed to the low recombination resistance at the photoelectrode/PGE interface, which will be examined in the subsequent section.

\subsection{EIS analysis of the QS-DSSC without and with differ- ent amounts of MMT nanofillers}

To demonstrate how the presence of MMT influences the charge transport characteristics in the PGEs, an EIS analysis was performed for the QS-DSSCs using different amounts of MMT nanofillers under dark conditions. Figure 3 shows Nyquist plots of the QS-DSSCs without and with 5 wt.\% MMT NF at $0.65 \mathrm{~V}$, which show three semi-circles in the frequency range of $20 \mathrm{mHz}$ to $65 \mathrm{KHz}$. The first, second, and third semicircles (from left to right), respectively relate to the charge transfer resistance at the PGE/ Pt-CE interface $\left(R_{\mathrm{Pt}}\right)$, the recombination resistance at the dye-sensitized photoelectrod/PGE interface $\left(\mathrm{RTiO}_{2}\right.$ or $\left.R_{\mathrm{ct}}\right)$, and the Warburg iodide/triiodide diffusion process $\left(R_{\text {diff }}\right)$ in the PGE. The $R_{\mathrm{Pt}}, R_{\mathrm{ct}}$ and $R_{\text {diff }}$ were obtained by fitting the EIS curves to an equivalent circuit, as presented in Fig. 3. Table 2 implies that the $R_{\mathrm{Pt}}$ was $5.80 \Omega$ for the DSSC using pure PVDF-HFP PGE, which enhanced to $6.03 \Omega$ for the DSSC using $5 \mathrm{wt}$ \% MMT. Then, the $R_{\mathrm{Pt}}$ either reduced or improved with increases in the amounts of MMT nanofillers in the cells. For a QS-DSSC using 15 wt.\% MMT, a low $R_{\mathrm{Pt}}$ value of $3.61 \Omega$ was acquired. This value was considerably lower than that acquired for the DSSC using pure PGE. Although the QS-DSSC using 15 wt.\% MMT had a low $R_{\mathrm{Pt}}$, a 
Table $1 \quad J-V$ parameters of QS-DSSCs prepared with 0-25 wt.\% of MMT nanofillers introduced into the PGE at 1 sun conditions.

\begin{tabular}{ccccc}
\hline $\begin{array}{c}\text { PGE with MMT } \\
\text { nanofillers }\end{array}$ & $J_{\text {sc }}\left(\mathrm{mA} \mathrm{cm}^{-2}\right)$ & $\begin{array}{c}V_{\text {oc }} \\
(\mathrm{V})\end{array}$ & FF & $\begin{array}{c}\text { PCE } \\
(\%)\end{array}$ \\
\hline MPN (liquid) & 14.10 & 0.750 & 0.64 & 6.77 \\
0 wt.\% MMT & 12.78 & 0.738 & 0.67 & 6.28 \\
5 wt.\% MMT & 15.15 & 0.681 & 0.66 & 6.77 \\
10 wt.\% MMT & 14.49 & 0.701 & 0.65 & 6.58 \\
15 wt.\% MMT & 14.38 & 0.697 & 0.64 & 6.48 \\
25 wt.\% MMT & 15.04 & 0.678 & 0.64 & 6.46 \\
\hline
\end{tabular}

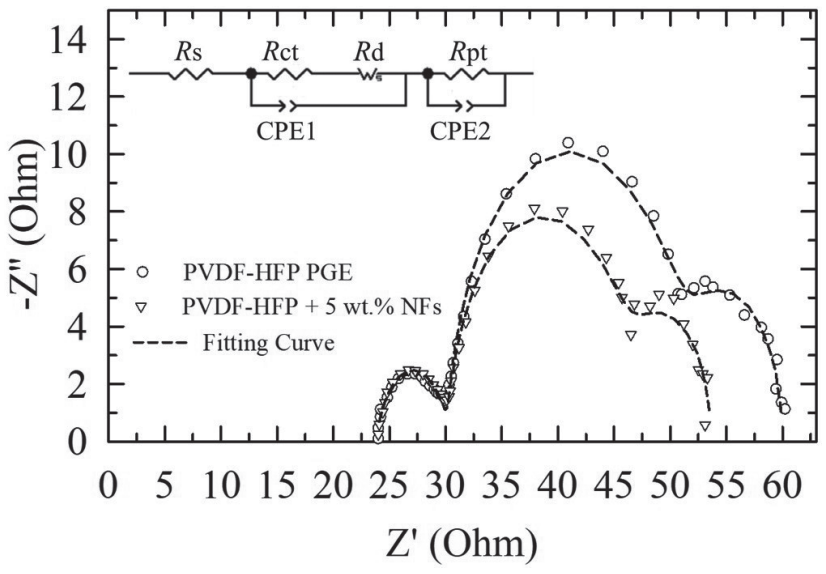

Fig. 3 EIS curves measured for the cells using pure PGE and PGE with 5 wt.\% MMT nanofillers.

high PCE was obtained for the QS-DSSC using 5 wt.\% MMT. This result denotes that $R_{\mathrm{Pt}}$ is not a main factor determining the PCEs of the cells using MMT nanofillers. For the values related to the $R_{\mathrm{ct}}$, the addition of MMT nanofillers into the PGEs resulted in a decrease in $R_{\text {ct }}$. Lower values of $R_{\mathrm{ct}}$ were measured for the QS-DSSCs with different amounts of MMT nanofillers than were measured without NF. The decrease in $R_{\mathrm{ct}}$ in the presence of MMT nanofillers revealed marked recombination at the photoelectrode/PGE interface. The result was consistent with the decreased $V_{\text {ос }}$ in the QS-DSSCs using MMT nanofillers. Table 2 also reveals that the QS-DSSC using pure PGE had an $R_{\text {diff }}$ value of $10.58 \Omega$. In the presence of 5 wt.\% MMT, the value reduced markedly to $6.11 \Omega$. The marked decrease in the $R_{\text {diff }}$ value indicates that the presence of 5 wt.\% MMT can improve the diffusion rate of the iodide/triiodide redox couples in the PGEs. These results are also consistent with the ion diffusivity values of the PGEs with various amount of MMT nanofillers. The $R_{\text {diff }}$ values have a significant relationship with the $J_{\text {sc }}$ values of the related cells. As shown in Table 1, the $J_{\mathrm{sc}}$ values increased from $12.78 \mathrm{~mA} \mathrm{~cm}^{-2}$ to $15.15 \mathrm{~mA} \mathrm{~cm}^{-2}$ with the addition of 5 wt.\% MMT nanofillers into the PGE and then reduced with
Table 2 EIS parameters obtained for the QS-DSSCs using PGEs with 0-25 wt.\% of MMT nanofillers.

\begin{tabular}{cccc}
\hline PGE with MMT NFs & $\begin{array}{c}R_{\mathrm{Pt}} \\
\left(\Omega \mathrm{cm}^{2}\right)\end{array}$ & $\begin{array}{c}R_{\mathrm{ct}} \\
\left(\Omega \mathrm{cm}^{2}\right)\end{array}$ & $\begin{array}{c}R_{\text {diff }} \\
\left(\Omega \mathrm{cm}^{2}\right)\end{array}$ \\
\hline 0 wt.\% MMT & 5.80 & 21.66 & 10.58 \\
5 wt.\% MMT & 6.03 & 16.41 & 6.11 \\
10 wt.\% MMT & 7.67 & 15.80 & 9.43 \\
15 wt.\% MMT & 3.61 & 15.81 & 7.51 \\
25 wt.\% MMT & 4.97 & 15.04 & 7.64 \\
\hline
\end{tabular}

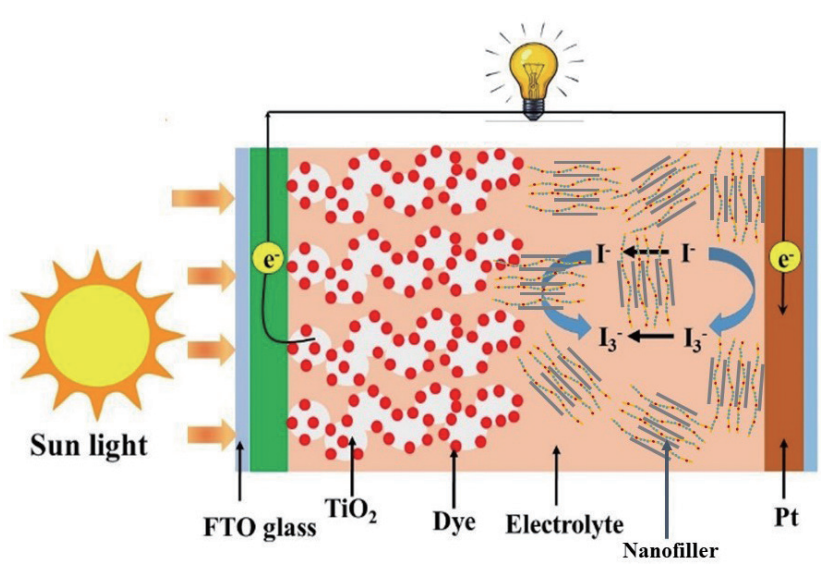

Fig. 4 Schematic diagram of a QS-DSSCs using MMT nanofillers.

further increases in the MMT amount in the PGEs. Compared to the QS-DSSC without nanofillers, the lower $R_{\text {diff }}$ of the QS-DSSCs with $5 \mathrm{wt}$ \% MMT contribute to their higher $J_{\text {sc }}$ value. It is well known that the presence of MMT in electrolytes reduces the ion pair formation. When MMT nanofillers are added to the PGEs, the polymer chains are entangled and confined by MMT nanofillers in which absorbed electrolytes are moved diagonally and increase the ion transfer characteristics in the electrolytes (Fig. 1). These two factors may be responsible for the lower $R_{\text {diff }}$ of the QS-DSSCs using 5 wt.\% MMT. Therefore, the cell using 5 wt.\% MMT nanofillers achieved a high PCE of $6.77 \%$. 


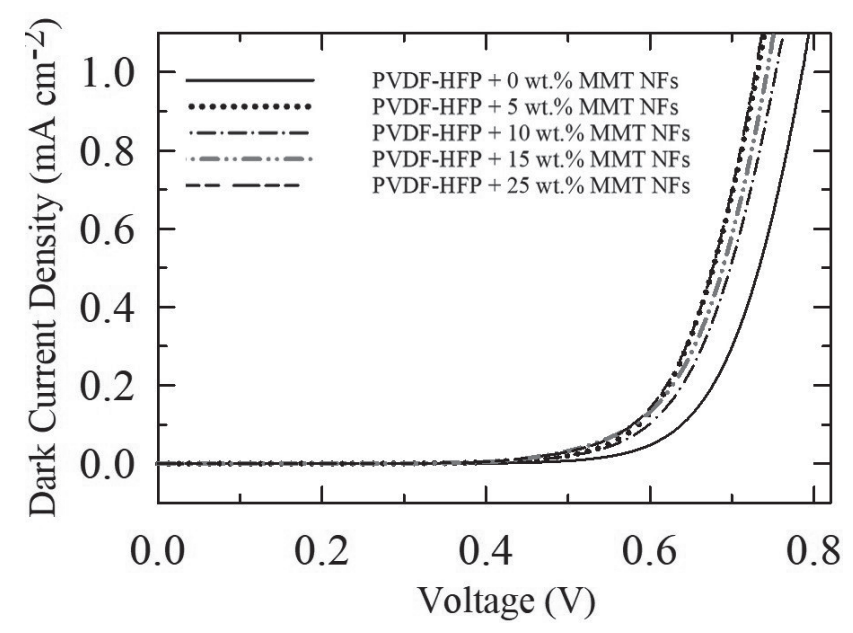

Fig. 5 Dark current density-voltage curves for the cells using PGEs with 0-25 wt.\% MMT nanofillers.

The mechanism for improvements of cell performance in the presence of MMT nanofillers is given in Fig. 4. The dark current is an important characteristic commonly utilized to assess the recombination of electrons in cells, which is assessed from the photoelectrode to electrolyte under dark conditions $^{22)}$. For the cells with and without different amount of MMT nanofillers, the dark current was measured at various applied potentials, for which the related outcomes are presented in Fig. 5. The dark current is higher for the PGE with different amounts of MMT nanofillers than it is in those without nanofillers, which is consistent with the lower recombination resistance. The presence of MMT nanofillers caused an increase in the dark current, proving high electron recombination at the photoelectrode/ PGE interface. Therefore, the $V_{\text {ос }}$ decreased markedly in the QS-DSSCs using different amounts of MMT nanofillers. The dark current acquired for the QS-DSSC using 5 wt.\% MMT nanofillers was inconsistent with the conductivity of the PGEs with 5 wt.\% MMT nanofillers, indicating that the conductivity of the PGEs was not the main factor influencing the electron recombination at the interface. This thus indicated that the MMT nanofillers in the PGEs can adsorb on the photoanode, facilitating the recombination reaction between the excited electrons in the photoelectrode and the iodide ions in the PGEs.

\subsection{Comparison among the performance of reported QS- DSSCs based on NCEs}

In the literature, only some reports described the applications of MMT-based NCEs on QS-DSSCs ${ }^{26-30)}$ (Table 3). In 2008, Tu et al. prepared a NCE system using a polymer, poly (N-isopropylacrylamide) (PNIPAAm), an unmodified MMT and an ACN-based iodide $\mathrm{LE}^{26)}$. In that study, a PCE of $5.41 \%$ was obtained for the cell using NCE. This PCE was $2.24 \%$ higher than the efficiency of a cell using pure PGE. The high cell efficiency was due to the high $R_{\mathrm{ct}}$, low $R_{\mathrm{Pt}}$ and $R_{\text {diff }}$ in NCE-based cell. Following this study, Ito et $a l$. prepared a NCE system using $\mathrm{P}$ (EO-EPI) polymer and MMT for GBL-based $\mathrm{LE}^{27)}$. The PCE of a QS-DSSC based on this NCE was $3.2 \%$. In 2009, Lai et al. introduced a system using PVDF-HFP and Triton modified MMT as the gelator and nanofillers, respectively ${ }^{28)}$. An MPN-based iodide electrolyte was employed to prepare the NCEs. In that work, a PCE of 5.20\% was obtained for the cell using a NCE. In 2011, Geng et al. prepared a NCE based on MMT nanofillers and an iodide PEO PGE ${ }^{29)}$. The ionic diffusivity and conductivity of the NCE was higher than that of the pure PGE. The PCE of the cell with this NCE was $4.70 \%$.

Table 3 Comparisons among the characteristics of reported MMT NFs-based PGEs and the related performance of QSDSSCs.

\begin{tabular}{|c|c|c|c|c|c|c|c|c|c|c|c|}
\hline References & $\begin{array}{c}\text { Polymer } \\
\text { utilized }\end{array}$ & Electrolyte & $\begin{array}{l}\mathrm{D} \times 10^{-6} \\
\left(\mathrm{~cm}^{2} \mathrm{~s}^{-1}\right)\end{array}$ & $\begin{array}{l}\sigma \times 10^{-3} \\
\left(\mathrm{~S} \mathrm{~cm}^{-1}\right)\end{array}$ & $\begin{array}{c}R_{\mathrm{Pt}} \\
\left(\Omega \mathrm{cm}^{2}\right)\end{array}$ & $\begin{array}{c}R_{\mathrm{ct}} \\
\left(\Omega \mathrm{cm}^{2}\right)\end{array}$ & $\begin{array}{c}R_{\mathrm{diff}} \\
\left(\Omega \mathrm{cm}^{2}\right)\end{array}$ & $\begin{array}{c}J_{\mathrm{sc}} \\
\left(\mathrm{mA} \mathrm{cm}^{-2}\right)\end{array}$ & $\begin{array}{l}V_{\mathrm{oc}} \\
(\mathrm{V})\end{array}$ & $\mathrm{FF}$ & $\begin{array}{l}\mathrm{PCE} \\
(\%)\end{array}$ \\
\hline \multirow{2}{*}{$\begin{array}{l}\text { Tu et al. } 2008 \\
\text { (ref.26) }\end{array}$} & \multirow[t]{2}{*}{ PNIPAAm } & ACN-PGE & & & 10.1 & 29.43 & 59.15 & 7.28 & 0.72 & 0.60 & 3.17 \\
\hline & & PGE+exfoliated-MMT & & & 9.46 & 13.37 & 16.58 & 12.6 & 0.73 & 0.59 & 5.41 \\
\hline \multirow{2}{*}{$\begin{array}{l}\text { Ito et al. } 2008 \\
\text { (ref. 27) }\end{array}$} & \multirow[t]{2}{*}{$\mathrm{P}(\mathrm{EO}-\mathrm{EPI})$} & GBL-PGE & & 0.16 & & & & & & & \\
\hline & & $\mathrm{PGE}+\mathrm{MMT}^{-N R^{4+}}(\mathrm{GBL})$ & & 0.34 & & & & 0.80 & 0.49 & 0.53 & 3.2 \\
\hline $\begin{array}{l}\text { Lai. et al. } 2009 \\
\text { (ref.28) }\end{array}$ & PVDF-HFP & MPN-PGE+MMT-Triton & & & 24.9 & 48.3 & 11.9 & 13.00 & & & 5.20 \\
\hline \multirow{2}{*}{$\begin{array}{l}\text { Geng et al. } 2011 \\
\text { (ref. 29) }\end{array}$} & \multirow[t]{2}{*}{ PEO } & MPN-PGE & 1.29 & 6.12 & 17.6 & 29.62 & 11.57 & & & & 4.21 \\
\hline & & PGE+MMT & 1.47 & 6.54 & 14.4 & $\begin{array}{l}31.98 \\
\text { (dark) }\end{array}$ & 11.91 & & & & 4.70 \\
\hline \multirow{3}{*}{$\begin{array}{l}\text { Prabakaran et al. } \\
2015 \text { (ref. 30) }\end{array}$} & \multirow{3}{*}{$\begin{array}{l}\text { PVDF-HFP/ } \\
\text { PEO }\end{array}$} & EC/PC-PGE & 0.0012 & 0.12 & & & & 2.10 & 0.67 & 0.48 & 0.7 \\
\hline & & PGE+MMT & 0.0030 & 0.54 & 12.4 & 42.0 & 30.7 & 5.20 & 0.71 & 0.62 & 2.3 \\
\hline & & PGE+ex MMT & 0.0048 & 2.52 & 14.2 & 40.8 & 20.0 & 7.70 & 0.73 & 0.68 & 3.8 \\
\hline \multirow[t]{3}{*}{ This study } & \multirow[t]{3}{*}{ PVDF-HFP } & MPN-Liquid & & & & & & 14.10 & 0.750 & 0.64 & 6.77 \\
\hline & & MPN-PGE & 6.77 & 1.01 & 5.80 & 21.66 & 10.58 & 12.78 & 0.738 & 0.67 & 6.28 \\
\hline & & PGE+MMT & 7.32 & 2.17 & 6.03 & 16.41 & 6.11 & 15.15 & 0.681 & 0.66 & 6.77 \\
\hline
\end{tabular}




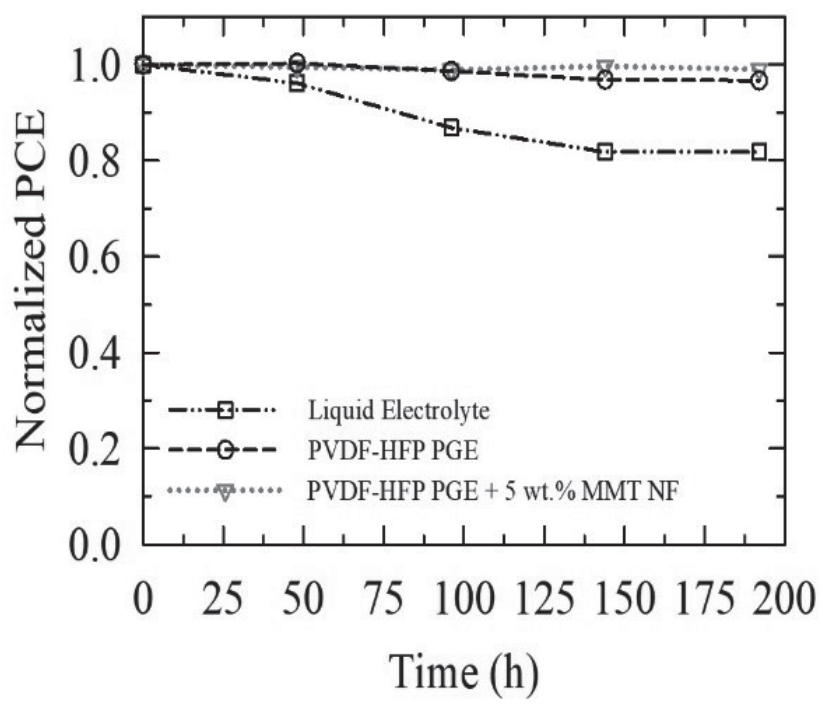

Fig. 6 Stability test of the cells prepared using the LEs, pure PGE and PGE with 5 wt.\% MMT nanofillers.

This efficiency was higher than of the cell with pure PGE. The cell with NCE had lower $R_{\mathrm{Pt}}$ and higher $R_{\mathrm{ct}}$ as compared to the cell using PGE, which were favorable for a high PCE. In 2015, Prabakaran et al. reported a NCE systems using PVDF-HFP/PEO and exfoliated MMT for an $\mathrm{EC} / \mathrm{PC}$-based $\mathrm{LE}^{30)}$. In that report, the ionic conductivity and diffusivity were higher in exfoliated MMT-based NCE than in pure MMT-based NCE and pure PGE. The cell using the exfoliated MMT-based NCE had higher $J_{\mathrm{sc}}, V_{\text {oc }}$ and PCE than the cells using the other electrolytes. The high cell performance was ascribed to the low $R_{\text {diff }}$ in the cell using exfoliated-MMT-based NCE. In this work, an MPN-based LE, a PVDF-HFP polymer and an unmodified MMT were utilized to prepare the NCEs aiming to increase the performance of the DSSCs. The result indicates that the addition of MMT NF into the PVDF-HFP PGE can increase the PCE (from $6.28 \%$ to $6.77 \%$ ) to a value similar to that of the liquid version $(6.77 \%)$. The high PCE was ascribed to the high ion diffusivity, electrolyte conductivity and low $R_{\text {diff }}$ in the NCE-based DSSCs. Furthermore, this PCE is the best among the reported PCEs in Table 3.

\subsection{Stability of the DSSCs}

An analysis of the stability of the DSSCs prepared using the LEs and PGEs with and without 5 wt.\% MMT was made with a long-term performance analysis executed under AM 1.5 conditions at $60^{\circ} \mathrm{C}$. The normalized PCEs of the DSSCs using LE, pure PGE and PGEs with 5 wt. \% MMT nanofillers are given in Fig. 6. For the cells using LEs, the PCE was considerably reduced. The PCE of the DSSC using LEs after the $192 \mathrm{~h}$ test was only $86 \%$. For the DSSC utilizing pure PVDF-HFP PGEs, the PCE was $96.6 \%$ of its initial value after the $192 \mathrm{~h}$ test, revealing better stability in comparison to the DSSCs using LEs. For the DSSCs utiliz- ing PGE with 5\% MMT nanofillers, the PCE was almost as same as that of the cell using pure PGE at the first phase of the experiment (until $100 \mathrm{~h}$ ). Afterwards, the PCE increased slightly with increases in the testing time. After the 196 h test, the PCE was $99.6 \%$ of its initial value, indicating the better stability the cells using PGE with 5 wt.\% MMT as compared to those using pure PGE.

\section{Conclusion}

The MMT/PVDF-HFP-based electrolytes were demonstrated to be efficient electrolytes for QS-DSSC applications. The presence of 5 wt. \% MMT in the PGEs had a marked impact on increasing the ion diffusivity and conductivity of the electrolytes. Although the presence of MMT reduced the $R_{\mathrm{ct}}$ and increased the $R_{\mathrm{Pt}}$, it considerably decreased the $R_{\text {diff }}$ of the DSSCs. The DSSCs using PGE with 5 wt. \% MMT obtained a PCE of $6.77 \%$. This PCE was higher than that of the cells using pure PGE (6.28\%) and similar to that of the cells using LEs $(6.77 \%)$, which was mainly ascribed to the improvement in the $J_{\mathrm{sc}}$ of the QSDSSCs. The stability of the DSSCs using PGEs can be improved by the addition of 5 wt. \% MMT into the PGEs. The cells using PGE with 5 wt.\% MMT nanofillers were able to maintain the initial PCE of $99.6 \%$ after the 196 h test.

\section{Acknowledgements}

Financial grants were supported by the Ministry of Science and Technology of Taiwan under projects MOST 106-2119-M-006-003, 106-2221-E-006-197-MY3 are acknowldged.

\section{References}

1) Yun, S.; Qin, Y.; Uhl, A.R.; Vlachopoulos, N.; Yin, M.; Li, D.; Han, X.; Hagfeldt, A. New-generation integrated devices based on dye-sensitized and perovskite solar cells. Energy Environ. Sci. 11, 476-526 (2018).

2) Urbani, M.; Ragoussi, M-E.; Nazeeruddin, M.K.; Torres, T. Phthalocyanines for dye-sensitized solar cells. Coord. Chem. Rev. 381, 1-64(2019).

3) Maeda, K.; Mallouk, T.E. Two-dimensional metal oxide nanosheets as building blocks for artificial photosynthetic assemblies. Bull. Chem. Soc. Jpn. 92, 38-54 (2019).

4) Cheema, H.; Baumann, A.; Loya, E.K.; Brigdon, P.; McNamara, L.E.; Carpenter, C.A.; Hammer, N.I.; Mathew, S.; Risko, C.; Delcamp, J.H. Near-infrared-absorbing indolizine-porphyrin push pull dye for dye-sensitized solar Cells. ACS Appl. Mater. Interfaces 11, 16474- 
16489 (2019).

5) Seo, S.M.; Kim, C.K.; Kim, H.K. Well-defined triblock copolymer $/ \mathrm{TiO}_{2}$ composite gel electrolytes for highperformance dye-sensitized solar cells. J. Mater. Chem. A 7, 14743-14752(2019).

6) Chiang, C.C.P.; Hung, C.Y.; Chou, S.W.; Shyue, J.J.; Cheng, K.Y.; Chang, P.J.; Yang, Y.Y.; Lin, C.Y.; Chang, T.K.; Chi, Y.; Chou, H.L.; Chou, P.T. PtCoFe nanowire cathodes boost short-circuit currents of Ru(II)-based dye-sensitized solar cells to a power conversion efficiency of 12.29\%. Adv. Funct. Mater. 28, 1703282 (2018).

7) Mathew, S.; Yella, A.; Gao, P.; Humphry-Baker, R.; Curchod, B.F.E.; Ashari-Astani, N.; Tavernelli, I.; Rothlisberger, U.; Nazeeruddin, M.K.; Grätzel, M. Dye-sensitized solar cells with $13 \%$ efficiency achieved through the molecular engineering of porphyrin sensitizers. Nat. Chem. 6, 242-247 (2014).

8) Kakiage, K.; Aoyama, Y.; Yano, T.; Oya, K.; Fujisawa, J.I.; Hanaya, M. Highly-efficient dye-sensitized solar cells with collaborative censitization by silyl-anchor and carboxy-anchor dyes. Chem. Commun. 51, 15894$15897(2015)$.

9) Durrant, J.R.; Haque, S.A. Solar cells: A solid compromise. Nat. Mater. 2, 362-363 (2003).

10) Ni, Y.; Jin, Z.; Fu, Y. Electrodeposition of P-Type CuSCN thin films by a new aqueous electrolyte with triethanolamine chelation. J. Am. Ceram. Soc. 90, 29662973 (2007).

11) Fabregat-Santiago, F.; Bisquert, J.; Cevey, L.; Chen, P.; Wang, M.; Zakeeruddin, S.M.; Grätzel, M. Electron transport and recombination in solid-state dye solar cell with spiro-OMeTAD as hole conductor. J. Am. Chem. Soc. 131, 558-562(2009).

12) Bai, Y.; Cao, Y.; Zhang, J.; Wang, M.; Li, R.; Wang, P.; Zakeeruddin, S.M.; Grätzel, M. High-performance dyesensitized solar cells based on solvent-free electrolytes produced from Eutectic melts. Nat. Mater. 7, 626-630 (2008).

13) Pinpithak, P.; Kulkarni, A.; Chen, H.W.; Ikegami, M.; Miyasaka, T. Solid-state thin-film dye-sensitized solar cell co-sensitized with methylammonium lead bromide perovskite. Bull. Chem. Soc. 91, 754-760(2018).

14) Decoppet, J.D.; Moehl, T.; Babkair, S.S.; Alzubaydi, R.A.; Ansari, A.A.; Habib, S.S.; Zakeeruddin, S.M.; Schmidt, H.W.; Grätzel, M. Molecular gelation of ionic liquid-sulfolane mixtures, a solid electrolyte for high performance dye-sensitized solar Cells. J. Mater. Chem. A 2, 15972-15977(2014).

15) Weisspfennig, C.T.; Hollman, D.J.; Menelaou, C.; Stranks, S.D.; Joyce, H.J.; Johnston, M.B.; Snaith, H.J.; Herz, L.M. Dependence of dye regeneration and charge collection on the pore-filling fraction in solidstate dye-sensitized solar cells. Adv. Funct. Mater. 24,
668-677 (2014).

16) Wu, J.; Lan, Z.; Lin, J.; Huang, M.; Huang, Y.; Fan, L.; Luo, G. Electrolytes in dye-sensitized solar cells. Chem. Rev. 115, 2136-2173(2015).

17) Nei De Freitas, J.; Nogueira, A.F.; De Paoli, M.A. New insights into dye-sensitized solar cells with polymer electrolytes. J. Mater. Chem. 19, 5279-5294(2009).

18) Chen, C.L.; Teng, H.; Lee, Y.L. In situ gelation of electrolytes for highly efficient gel-state dye-sensitized solar cells. Adv. Mater. 23, 4199-4204(2011).

19) Dissanayake, M.A.K.L.; Divarathne, H.K.D.W.M.N.R.; Thotawatthage, C.A.; Dissanayake, C.B.; Senadeera, G.K.R.; Bandara, B.M.R. Dye-sensitized solar cells based on electrospun polyacrylonitrile(PAN) nanofibre membrane gel electrolyte. Electrochim. Acta 130, 76-81 (2014).

20) Xiang, W.; Huang, W.; Bach, U.; Spiccia, L. Stable high efficiency dye-sensitized solar Cells based on a cobalt polymer gel electrolyte. Chem. Commun. 49, 89978999 (2013).

21) Venkatesan, S.; Lee, Y.-L. Nanofillers in the electrolytes of dyesensitized solar cells. Coord. Chem. Rev. 58, 58-112(2017).

22) Venkatesan, S.; Liu, I.P.; Lin, J.C.; Tsai, M.H.; Teng, H.; Lee, Y.L. Highly efficient quasi-solid-state dye-sensitized solar cells using polyethylene oxide(PEO) and poly (methyl methacrylate) (PMMA)-Based printable electrolytes. J. Mater. Chem. A 6, 10085-10094 (2018).

23) Venkatesan, S.; Surya Darlim, E.; Tsai, M.H.; Teng, H.; Lee, Y.L. Graphene oxide sponge as nanofillers in printable electrolytes in high-performance quasi-solidstate dye-sensitized solar cells. ACS Appl. Mater. Interfaces 10, 10955-10964(2018).

24) Liu, I.-P.; Hung, W.-N.; Teng, H.; Venkatesan, S.; Lin, J.-C.; Lee, Y.-L. High-performance printable electrolytes for dye-sensitized solar cells. J. Mater. Chem. A 5, 9190-9197 (2017).

25) Venkatesan, S.; Liu, I.P.; Hung, W.N.; Teng, H.; Lee, Y.L. Highly efficient quasi-solid-state dye-Sensitized solar cells prepared by printable electrolytes for room light applications. Chem. Eng. J. 367, 17-24(2019).

26) Tu, C.W.; Liu, K.Y.; Chien, A.T.; Yen, M.H.; Weng, T.H.; Ho, K.C.; Lin, K.F. Enhancement of photocurrent of polymer-gelled dye-sensitized solar cell by incorporation of exfoliated montmorillonite nanoplatelets. $J$. Polym. Sci. Part A Polym. Chem. 46, 47-53(2008).

27) Ito, B.I.; De Freitas, J.N.; De Paoli, M.A.; Nogueira, A.F. Application of a composite polymer electrolyte based on montmorillonite in dye-sensitized solar cells. $J$. Braz. Chem. Soc. 19, 688-696(2008).

28) Lai, Y.H.; Chiu, C.W.; Chen, J.G.; Wang, C.C.; Lin, J.J.; Lin, K.F.; Ho, K.C. Enhancing the performance of dyesensitized solar cells by incorporating nanosilicate 
platelets in gel electrolyte. Sol. Energy Mater. Sol. Cells 93, 1860-1864(2009).

29) Geng, Y.; Shi, Y.; Wang, L.; Ma, B.; Gao, R.; Zhu, Y.; Dong, H.; Qiu, Y. Photovoltage improvements and recombination suppression by montmorillonite addition to PEO gel electrolyte for dye-sensitized solar cells.
Phys. Chem. Chem. Phys. 13, 2417-2421 (2011).

30) Prabakaran, K.; Mohanty, S.; Nayak, S.K. Chemically exfoliated nanosilicate platelet hybridized polymer electrolytes for solid state dye sensitized solar cells. New J. Chem. 39, 8602-8613(2015). 